Made available courtesy of Human Kinetics: http://journals.humankinetics.com/jpah

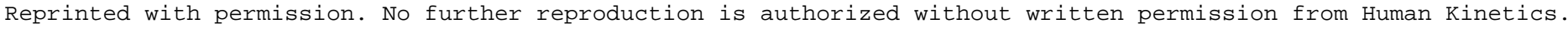

\title{
Active Living in the Trucking Sector: Environmental Barriers and Health Promotion Strategies
}

\author{
Yorghos Apostolopoulos, Mona M. Shattell, Sevil Sönmez, Robert Strack, \\ Lauren Haldeman, and Victoria Jones
}

\begin{abstract}
Background: As one of the most underserved segments of the U.S. labor force, truck drivers have been associated with a series of morbid conditions intimately linked to their occupational milieux, their mostly unhealthful nutritional intake and sedentary lifestyles, and their resulting excess weight-gain. Methods: This paper reports data from a baseline assessment of 25 trucking work settings located around interstate highways I-40 and I-85 in North Carolina. It examines how the environmental attributes of these work settings influence the physical and recreational activity behaviors of truckers, compares findings with those from other occupational environments, and brings to the fore a new health promotion paradigm for trucking worksites. Results: Findings support growing empirical and anecdotal evidence that trucking work settings remain not only active-living deserts, but overall unhealthful places. A scan of physical, social, and information environments within trucking worksites as well as physical environments of surrounding communities reveal only meager opportunities for physical and recreational activity for truckers. Conclusion: This paper places the highly underserved population of truckers firmly within the discourse of worksite health promotion, and calls for comprehensive multistakeholder wellness strategies that address a multitude of risk factors linked to the occupational context.
\end{abstract}

Keywords: trucking worksites, environmental barriers, physical activity, obesity-associated morbidities

Obesity-associated comorbidities in the United States (U.S.) have been increasing at alarming rates, ${ }^{1}$ and not surprisingly, medical expenditures attributed to obesity reached a record $\$ 147$ billion in $2008 .^{2}$ Considerable declines in mobility patterns at home, work, leisure, and during travel have resulted in substantial reductions in individuals' energy expenditures with subsequent negative ramifications on public health. Regular physical activity can mitigate weight gain and reduce blood pressure, reduce the risk for type- 2 diabetes, as well as risks for CVD, cancer, arthritis-associated disabilities and osteoporosis, and can relieve symptoms of depression and anxiety, and improve psychological health and sleep quality. 1,3

Ecological domains, such as governmental, corporate, organizational, community, and built-environment factors, can support or inhibit opportunities and resources available for physical and recreational activities. ${ }^{4-7}$ The availability of physical-activity resources and facilities

\footnotetext{
Apostolopoulos, Strack, and Jones are with the Dept of Public Health Education, University of North Carolina at Greensboro. Shattell is with the School of Nursing, DePaul University, Chicago, IL. Sönmez is with the Bryan School of Business and Economics at the University of North Carolina at Greensboro. Haldeman is with the Dept of Nutrition, University of North Carolina at Greensboro.
}

and their equitable distribution across diverse socioeconomic and geographic landscapes is intimately linked to health behaviors. ${ }^{8}$ Inequities in environmental supports for physical activity may underlie broad health disparities across different demographics and occupations.

Worksites have a critical bearing on employees' physical-activity patterns. They can provide resources to facilitate physical activity and offer opportunities that can influence individual behaviors. Conversely, work environments can restrict active-living behaviors by promoting sedentary behaviors or discouraging physical activity by limiting access to safe recreation, reducing availability of recreational facilities, or simply as a result of their location far from public-transit options. As a result, many companies have used physical-activity promotion as a strategic corporate priority to improve employee health and productivity, and in turn, business performance. ${ }^{9}$ Moreover, a multitude of neighborhood and built-environment factors have been linked with barriers to or enablers of active living. 8

Several million truckers operate within a transportation environment that includes multicomponent workplaces, along with policies and regulations that govern them. ${ }^{10}$ Truckers' burden of disease, lack of access to health-promotive resources, limited access to health care, and scale of occupational hazards associated with their profession indicate that trucking is among the most underserved occupational segments. Truck drivers work within 
intertwined mechanisms of government regulations, trucking-sector operations, corporate policies governing trucking worksites, and the trucking built-environment. ${ }^{10}$ This occupational context influences truckers' foodpurchasing choices, the number of hours they sleep, the quality of air they breathe, as well as their opportunities for physical activity. Within this work environment, only $8 \%$ of truckers exercise regularly due to lack of fitness resources, about $85 \%$ are overweight or obese, and $44 \%$ are hypertensive, while many suffer from CVD, type- 2 diabetes, or metabolic syndrome. ${ }^{1-13}$ Life expectancy is 63 years among unionized drivers and a startlingly low 55.7 years among members of the Owner-Operator Independent Drivers Association. ${ }^{14}$ The annual medical costs for obese truckers are $\$ 1,792$ compared with $\$ 1,012$ for those at a normal weight. ${ }^{15}$ Given that the trucking worksite environment can support employee physical activity and nutrition patterns and considering that U.S. truck drivers are at higher risk for mortality and obesitythe detrimental role of the absence of a supportive work environment becomes clear.

This article aims to place the trucking sector within the discourse of worksite health promotion. Specifically, it 1) examines how the environmental attributes of trucking worksites influence the physical and recreational activity patterns of truckers and 2) describes a comprehensive, multilevel, multistakeholder worksite health-promotion paradigm tailored to the needs of the trucking sector.

\section{Methods}

\section{Instrument Development}

Grounded in social ecological models ${ }^{16-18}$ and based on existing tools that assess eating and active-living environments, the Healthy Trucking Worksites Audit Instrument (HEATWAI) was designed to assess the health-promotive characteristics of trucking work settings. ${ }^{19}$ The HEATWAI is a 250-item instrument that uses observation to measure the presence of those corporate, social, and built-environment attributes of trucking worksites that positively influence food choices/eating behaviors and physical/recreational activities of truckers and other transportation and warehousing sector employees.

The development of HEATWAI items evolved through an incremental process of multiple observations at truckstops, trucking terminals, warehouses, highway rest areas, and truck cabs. The first draft of the instrument was pilot-tested, after which results were discussed by members of the research team, and following consensus, appropriate changes were made. Following a similar mode of operations, the observational process continued until the research team reached a consensus on the final version. Baseline reliability data were collected independently by 2 researchers (different from those who piloted HEATWAI, to avoid inadvertently increasing its interrater reliability) during a single site visit, and interrater reliability analysis produced a Kappa $=0.87$

Table 1 HEATWAI Summary Scales and Subscales

\begin{tabular}{lc}
\hline Summary scales and subscales & Items \\
\hline Active Living Environment & $(65$ items total $)$ \\
- ALE subscale 1: support for physical and recreational activity in natural environments and & 13 items \\
surrounding grounds & 14 items \\
- ALE subscale 2: support for physical and recreational activity in built environment & 19 items \\
- ALE subscale 3: resources and facilities that encourage physical and recreational activity & 19 items \\
- ALE subscale 4: exercise and fitness facilities that support physical activity & $(15$ items total) \\
Health Supportive Social Environment & 7 items \\
• HSSE subscale 1: supportive social environment for physical and recreational activity & 8 items \\
• HSSE subscale 2: social support for healthful food options & $(24$ items total) \\
Health Supportive Community Environment & 13 items \\
- HSCE subscale 1: physical and recreational activity amenities and opportunities in community & 11 items \\
• HSCE subscale 2: healthful food options in community & $(11$ items total) \\
Health Information Environment & 5 items \\
• HIE subscale 1: evidence of physical and recreational activity promotion & 6 items \\
• HIE subscale 2: evidence of promotion of healthful food choices and eating behaviors & $(128$ items total) \\
Healthy Food Environment &
\end{tabular}


$(P<.001), 95 \%$ CI $(0.760-0.980)$. A description of the 5 HEATWAI components follows; with greater elaboration of the assessment of the active-living environment (HEATWAI scales and subscales are listed in Table 1).

HEATWAI Summary Scales and Subscales. The Active Living Environment scale (ALE) assesses the extent to which trucking worksites promote involvement in physical and recreational activities. It examined the availability of resources that support physical activity in the natural environment and on surrounding grounds (13 items), the built environment (eg, buildings, stairwells) (14 items), resources and facilities that encourage physical and recreational activities (19 items), and exercise and fitness facilities (19 items). In addition, the number of buildings, floors, stairs, and elevators along with the working condition of fitness equipment were assessed, while sedentary environments (eg, presence of TV lounge/ room, movie lounge/theater) were noted. The aggregate sum of the presence of physical activity-supportive characteristics resulted in a total score (65 items), and a number of summary scales were also created to measure its 4 components.

The Health-Supportive Social Environment scale (HSSE) measures the social environment related to food, physical/recreational activity, and weight-management at trucking worksites. Examples included 'whether worksites offer appealing, low-cost, healthful food options' or 'hold onsite sport events or physical activities' (eg, basketball, table tennis) ( 7 items on physical/recreational activities and 8 items on healthful food/eating). The total score was calculated from the sum of 15 items, as points were assigned when these characteristics were observed.

Finally, the Health-Supportive Community Environment scale (HSCE) was included to measure areas surrounding worksites, which are critical for truckers' food and physical activity-related decisions. Community was defined as the surrounding neighborhood of the worksite along with the area immediately visible from the worksite within the observer's view when standing directly outside the worksite or walking along its perimeter (usually up to a 2 to 3 block radius). A community that promotes physical/recreational activity was defined to include walking-designated areas around the immediate proximity of the worksite or fitness facilities (13 items). A community that promotes healthy eating was defined to include easily accessible produce-markets, greengrocers, or food stores selling unprocessed, healthy carryout items (11 items). In addition, items on the area's overall safety and cleanliness, as well as its walkability were included.

The Health Information Environment scale (HIE) included all visible health-related print media at trucking worksites that truckers are exposed to that have the potential to motivate healthful eating and physical activity.
All publicly visible bulletin boards, notices, postings, brochures, and fliers with relevant information messages were recorded for the purpose of assigning points. Eleven items assessed the presence of health-promotive media in the areas of nutrition, physical and recreational activities, as well as weight management. Eleven points was the maximum possible score for all items; summary scales were developed for physical/recreational activity (5 items) and healthful food/eating (6 items).

The Healthy Food Environment scale (HFE) measured the presence of healthful food options and resources in restaurants, vending machines, convenience stores, lunch-break rooms, drivers' lounges, and nearby picnic areas. The availability and condition of amenities (eg, microwaves, refrigerators, and filtered water coolers) were also recorded. The combined total score represented 128 possible points; but due to the large number of items, summary scales were established for each of the components. Results of our assessment of this component are not discussed in this paper.

HEATWAI Scoring. HEATWAI items measured environmental characteristics that had presumed positive effects on food/eating and physical/recreational activities; in certain cases, resources were recorded in terms of their number and condition. Each time an environmental characteristic considered to promote healthful food choices and physical/recreational activity was encountered (ie, presence of walking trails), points were assigned to that particular category. A scorecard was created to permit a total score for the entire worksite as well as scores for summary scales and subscales. Subsequently, an overall rating was developed to indicate the level of support for healthy living. When a particular worksite scored 90 to $100 \%$ of the maximum possible points, that worksite was assessed as being fully supportive of healthy living; a 75 to $89.9 \%$ score was considered mostly supportive; a 50 to $74.9 \%$ was considered partially supportive; a 35 to $49.9 \%$ was considered scarcely supportive; and less than $35 \%$ was considered to be not-at-all supportive of healthy living. Simply stated, the higher the score a worksite received, the more promotive of health it was rated.

\section{Data Collection and Analysis}

The study was approved by the university Institutional Review Board. Data were collected on both healthful eating and physical activity opportunities at trucking worksites; however, only those results from our assessment of the active-living environment of trucking work settings and surrounding communities are reported in this paper. Data were collected from 8 truckstops, 8 trucking terminals, 7 warehouses, and 2 highway rest areas, all located in south-central North Carolina in close proximity 
to interstate highways I-85 and I-40. Although truck cabs are a critical component of truck drivers' work settings, because the ergonomic nature and limited size of the truck cab does not offer opportunities for active living, and in fact, promotes sedentary behaviors, baseline data were not collected from this facet of the worksite. (It should be noted, therefore, that the worksite that truck drivers spend the greatest portion of their workday in, is the least promotive of active living.) Research sites were selected based on their representativeness of diverse geographic (rural vs. urban/suburban) and corporate (national/ regional vs. small/local) characteristics, highway proximity, and worksite size (mainly trucker traffic), as well as their importance as trucking worksites-based mainly on the amount of time drivers spend there and opportunities for physical/recreational activities and healthful eating. Onsite observation was conducted during daylight hours and lasted an average of 75 minutes per worksite. Observations at highway rest areas were the shortest, and those at truckstops were the longest, not all HEATWAI dimensions were present or applicable at every type of worksite. Data analysis included descriptive statistics and interrater correlation analysis so that key psychometric attributes of the environmental measure HEATWAI could be established.

\section{Results and Discussions}

\section{Trucking Worksites}

Trucking work settings include trucking terminals, warehouses, truckstops, highway rest areas, and truck cabs (Table 2). These multicomponent worksites comprise the framework of the transportation and warehousing sector; while it is difficult to classify them as conventional workplaces, in combination, they represent the trucking work environment. When truckers are not on the road, they load, unload, eat, sleep, rest, shower, communicate with their families, do their laundry, fuel, socialize, shop, and complete paperwork in these settings. In a sense, their work and personal lives are inextricably linked so that they spend nearly all of their time at some component of their broader worksites. The total daily number of hours that a trucker spends in such settings can vary by worksite type, time of day and phase of trip, and can range from about 30 minutes to well over 30 hours, when they remain at a truckstop or warehouse waiting for a load (Table 1). Even when they are not driving (which is a critical aspect of the profession), truckers spend substantial amounts of their time at trucking worksites. When employees of other occupations are able to go home after work, truck drivers who may be away from their homes for weeks at a time have little choice but to spend even their leisure time at or around their worksites until they are able to get to their homes for 1 or 2 weekends out of the month. Because of this characteristic of trucking, the health effects of the occupation and worksite environments are highly unique. Therefore, truckstops, where particularly long-haul truckers spend most of their nondriving time, have the opportunity to offer this captive audience of sorts varied opportunities for physical and recreational activities. ${ }^{20}$ Results of our assessments of the various components of the trucking worksite are offered in Tables 3 and 4 as total scores, maximum possible scores, and health-supportive ratings.

\section{Physical and Built Environment}

The specific attributes of the natural environment and surrounding grounds immediately around trucking worksites are closely linked to worksite type. Truckstops and highway rest areas are located along interstate highways adjacent to or surrounded by wooded areas or green spaces; trucking terminals and warehouses are predominantly located in industrial and socioeconomically depressed neighborhoods of urban centers. Therefore, the natural grounds of trucking worksites observed in this study, as a whole were not found to be conducive to physical and recreational activities. The presence of open green space, vegetation, well-maintained landscaping, as well as perceived safety, freedom from noise, and absence of diesel fumes, among other similar characteristics were recorded. The physical environment-receiving 1 point for the presence of each of these positive characteristics (or absence of unhealthful characteristics)—was scored 94 from a maximum of 325 possible points. This represents only $28.9 \%$ of total possible support from trucking worksites for physical and recreational activity and is interpreted as an environment that is not-at-all supportive of active living (Table 3 , Section 1 ).

The built environment is equally important as it has the potential to provide additional opportunities for physical activity. This dimension of observed trucking worksites was substantial, as they often include several adjoining buildings, large parking lots, loading docks and cranes, and a high volume of traffic. Most buildings had no more than 2 floors (mean number of floors $=1.6$; mean number of buildings $=6.3)$. Few worksites $(17 \%)$ had elevators and those with stairwells had very few steps (mean number per worksite $=13$ ). The few stairwells that were observed appeared visible and safe, although not especially appealing and also lacking signage designed to encourage their use. Settings where truckers spend large amounts of time (such as truckstops and rest areas) often have very few or no stairs and therefore provide no opportunities for use. The built environment was scored 88 out of a maximum of 330 possible points, which resulted in only a $26.7 \%$ support rating for physical activity (notat-all supportive of active living) (Table 3, Section 2).

\section{Resources for Physical and Recreational Activity}

The presence of resources and facilities that encourage physical and recreational activity may be the most significant aspect of trucking worksites-especially because they are the easiest to provide. We recorded the presence of a) outdoor pedestrian, walking, or running trails (in 
Table 2 Trucking Worksites and Hours of Service

\begin{tabular}{ll}
\hline Sites & Components and relationship to truckers \\
\hline Trucking terminals & $\begin{array}{l}\text { What they are: Commercial facilities responsible for handling and temporarily storing freight, pend- } \\
\text { ing transfers between distribution centers. Many are independent companies but most are operated by } \\
\text { trucking companies themselves. }\end{array}$
\end{tabular}

Relation to truckers: Truckers spend time at these locales as they wait for loads to be placed on/ removed from trucks ranging from less than 1 hour to several hours. There are limited opportunities for physical/recreational activities or healthful eating.

Warehouses

What they are: Commercial facilities responsible for keeping/storing merchandise secure and in good condition. Some warehouses provide logistical services such as labeling, inventory control management, repackaging, and transportation arrangement.

Relation to truckers: Truckers spend time at these locales as they wait for loads to be placed on/ removed from trucks ranging from less than 1 hour to several hours. There are limited opportunities for physical/recreational activities or healthful eating.

Truckstops

What they are: Commercial facilities that provide fuel, parking, food, mini-mart shops, laundromat, showers, truck washes and repairs, and other services. They are usually located on or near a busy road or highway. Truckstops across the country are owned/ operated by a number of large corporations and standardized in design and amenities.

Relation to truckers: Truckers use truckstops as a home-away-from-home. They eat, rest, do their laundry, take showers, refuel, get their trucks washed/maintained, watch TV/movies, and socialize with other truckers. Truckers can spend anywhere from 30 to 45 minutes, to their mandatory HoS daily break of about 10 hours, to well over 30 hours either as per their HoS or while waiting for loads or getting their trucks repaired or maintained. Opportunities for physical/recreational activities and healthful eating are extremely limited. Truckstops offer TV/movie lounges and video arcades but no exercise rooms, they offer a variety of unhealthy options (e.g., doughnuts, fried foods) but not very many fresh and whole food choices.

Highway rest areas What they are: Public facilities located next to highways where both commercial drivers and passengers can park, rest, or eat without exiting on to secondary roads.

Relation to truckers: Truckers park to rest, sleep, stretch, use restrooms, and to eat. They can spend anywhere between a 10-15 minute pit-stop break to several hours, depending on schedules and what food/beverage they have with them in their truck cabs. Most rest areas offer opportunities for walking and stretching, but few other physical/recreational activities. As for healthful eating, most offer a series of typical vending machines (with mostly unhealthful contents), while there are ample opportunities to eat outdoors at picnic tables.

Truck cabs

What it is: While away from their homes, the truck cab serves as truckers' home on the road and primary work space. Cabs are equipped with a sleeper berth, refrigerator, and communication equipment. They may also have entertainment technology as well as computer and Internet connection. What a truck cab houses has much to do with how the trucker lives and how much time he spends on the road.

Relation to truckers: Truckers eat, sleep, work, and socialize in their truck cabs. They can spend up to an astonishing 23 hours per day in their truck cab. There are clearly no opportunities for physical or recreational activity within the confines of a truck cab. As for healthful eating, it is possible only if truckers consciously stock up their refrigerators with healthy options (fresh and whole foods).

Note. Hours of Service $(\mathrm{HoS})$ can be best explained with an example: If a driver follows the 70-hour/8-day limit and works 14 hours for 5 days in a row, s/he will have been on duty for 70 hours. S/he would not be able to drive again until s/he drops below 70 hours worked in 18 -day period. However, if his/her company allows the use of the 34-hour restart provision, s/he would have driving time available immediately after 34 consecutive hours off duty. S/he would then begin a new period of 8 consecutive days and have 70 hours available. 


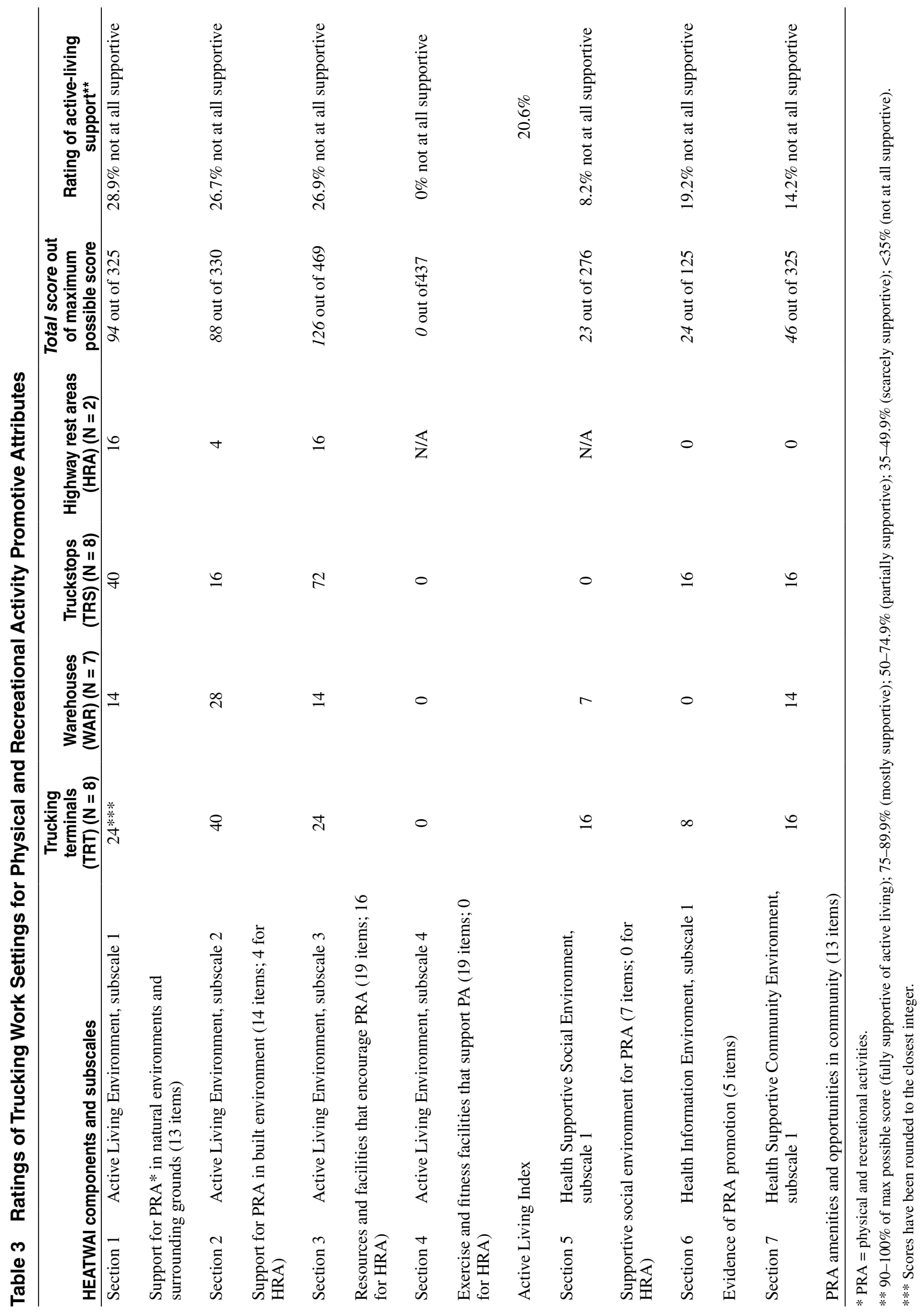


Table 4 Aggregate Active-Living Score by Type of Trucking Work Setting

\begin{tabular}{lcc}
\hline Aggregate HEATWAl scores & $\begin{array}{c}\text { Total score out of maximum } \\
\text { possible score }\end{array}$ & $\begin{array}{c}\text { Rating of active-living } \\
\text { support }^{\star *}\end{array}$ \\
\hline Trucking terminals & $128 *$ out of 760 & $\mathbf{1 6 . 8 \%}$ \\
Warehouses & 77 out of 665 & $\mathbf{1 1 . 6 \%}$ \\
Truckstops & 160 out of 760 & $\mathbf{2 1 . 1 \%}$ \\
Highway rest areas & 36 out of 102 & $\mathbf{3 5 . 3 \%}$ \\
All work settings & $\mathbf{4 0 1}$ out of $\mathbf{2 2 8 7}$ & $\mathbf{1 7 . 5 \%}$ \\
\hline
\end{tabular}

* Scores have been rounded to the closest integer.

** 90-100\% of max possible score (fully supportive of active living); 75-89.9\% (mostly supportive); 50-74.9\% (partially supportive); 35-49.9\% (scarcely supportive); $<35 \%$ (not at all supportive).

only 2 out of 25 observed worksites); b) outdoor paths, lanes, rack spaces, lockers, or rentals for bicycles (0 out of 25); c) in/outdoor recreational facilities or playgrounds, such as table tennis or pool tables, basketball, tennis, or racquetball courts (6 out of 25); and d) showers, lockers, weight scales, laundry machines, and/or spas (18 out of 25). Resources that encourage sedentary behaviors (ie, TV or movie lounge, video arcades) were observed in 13 out of 25 trucking worksites. Trucking worksites were scored 126 out of a total 469 possible points, or $26.9 \%$ of overall support (not-at-all supportive of physical/ recreational activity) (Table 3 , Section 3 ).

\section{Exercise and Fitness Facilities}

The presence of exercise and fitness facilities that support physical activity is a critical parameter for potential regular involvement in physical and recreational activities. Overall, we did not expect to find exercise and fitness facilities at trucking terminals and warehouses-not to mention highway rest areas with relatively few employees. Highway rest areas do, however, provide ample walking and other recreational opportunities, more often than not. But due to the volume of truckers passing through truckstops, we had anticipated the existence of some type of exercise room, strength/resistance equipment, or equipment used for cardiovascular exercise in a space not necessarily dedicated exclusively to fitness. Out of 23 sampled trucking worksites with over 750 staff that serve several thousand truckers each month, not one had even a mixed-use room that included some form of exercise or physical activity (eg, treadmills or stationary bikes in a TV room, a ping-pong table in a lounge). In this area, trucking worksites received 0 out of a total 437 possible points, or $0 \%$ of overall support (not-at-all supportive of physical/recreational activity) (Table 3 , Section 4).

\section{Information and Social Environments Promoting Active-Living}

The workplace can be ideal settings in which to establish a supportive social environment for physical and recreational activity and health promotion. In fact, both the perceived and actual support for exercise and physical activity within the worksite social space remains among the strongest independent predictors of individuals' physical activity. ${ }^{21}$ Workplace policies, colleagues, and supportive social networks are critical in defining health behaviors. ${ }^{22}$ Out of 25 observed trucking settings, not one provided free-of-charge or discounted fitness memberships, onsite sport teams, incentives for participation in physical or recreational activities, onsite organized physical or health promotion activities, wellness committees, onsite free-of-charge fitness assessments, or health risk appraisals. The active-living support rating for the social environment was the lowest among all components measured by HEATWAI - a disappointing 8.2\%, or a total score of 23 out of a possible 280 (not-at-all supportive) (Table 3, Section 5).

Looking at the health information environment for physical and recreational activity, bulletin boards, notices, postings, posters, brochures, and fliers containing informational messages on physical activity, availability of exercise classes, and weight management opportunities were recorded. The presence of print and other forms of health promotion and information media is important because this type of information has the potential to educate and influence health behaviors. At trucking worksites, the total score was 24 out of a possible 125 points or $19.2 \%$ (not-at-all supportive of active living) (Table 3, Section 6).

\section{Surrounding Communities as Promotive Environments for Active-Living}

While resources available within the boundaries of trucking worksites can directly influence involvement in physical and recreational activities, the neighborhood and broader community can provide important supplemental resources and opportunities. Unfortunately, communities around warehouses and trucking terminals offer limited opportunities for physical activity because they are often situated in socioeconomically depressed urban areas; whereas, highway rest areas and truckstops are mostly isolated due to their locations away from populated towns or cities. About $90 \%$ of the observed surrounding communities failed to offer easy access to parks, recreational facilities, playing grounds, or other 
in/outdoor recreational facilities. For over $95 \%$ of the observed communities, it was very difficult to access the closest community where fitness and/or recreational facilities could be found, due to the lack of availability of safe walking paths or a public transit system. In addition, lack of perceived safety due to evidence of crime and homelessness in several of the observed communities made any such attempt undesirable. Communities surrounding trucking worksites were scored 46 out of a maximum possible 325 points. In other words, overall community support for resources and amenities for physical and recreational activities was found to be only $14.2 \%$ (not-at-all supportive of active living) (Table 3, Section 7).

\section{Workplace Opportunities for Active- Living: Trucking vs. Other Occupations}

Using the 4 subscales of the Active Living Environment, an Active-Living Index was calculated to represent the combined attributes of the built and physical environments that promote physical/recreational activities, resources that promote physical/recreational activity, and exercise and/or fitness facilities. The Active-Living Index resulted in a low $20.6 \%$, which indicates that trucking worksites do not provide the resources necessary to encourage truckers' involvement in physical and recreational activities. While environmental supports for involvement in physical and recreational activities across the 7 HEATWAI components reported here were found to be poor, differences across types of trucking work settings, especially in light of the implications for future health promotion at various worksites, would be critical for the design and prioritization of interventions. Despite the small sample of highway rest areas assessed in this study, this particular type of work setting appears to provide the most supportive environments to truckers for physical and recreational activities due to their natural active-living features (ie, green spaces, walking trails). Therefore, this particular component of trucking work settings needs to be viewed in comparative terms. In fact, rest areas earned an active-living support rating of 35.3\% (in some cases more than twice as high as other settings), whereas truckstops received a $21.1 \%$, trucking terminals $16.8 \%$, and warehouses only $11.6 \%$ (Table 4 ). These 25 trucking work settings collectively do not present themselves as worksites supportive of physical/recreational activity because they do not offer even the minimum of resources, facilities and amenities required for participation in physical activity; in fact, the overall support for such behaviors is $17.5 \%$ (not-at-all supportive).

These findings further corroborate our working hypothesis that the trucking sector remains an overall underserved workplace, which can be directly linked to the predominantly blue-collar nature of its employees. ${ }^{17}$ Although this explanation still remains only a working assumption, it is indirectly supported by ample empirical studies documenting that, in general, minority and working-class occupational segments remain underserved in terms of access to health care, and healthful resources (eg, grocery stores, fitness facilities), and a higher burden of disease. ${ }^{23-25}$ Truck drivers are classified as one of the highest-risk occupational segments due to their elevated occupational hazards, but, as our findings support, they are also deprived of those organizational and institutional support systems critical to their personal health (eg, lack of physical activity resources and obesity risk) and public safety (eg, connections between lack of access to physical activity, elevated stress, sleep apnea, and increased accidents and crashes). ${ }^{26,27}$ As such, trucking work settings could be easily defined as active-living deserts, particularly because these ratings provide additional explanation and support in terms of truckers' exceedingly high morbidity and mortality rates. While this paper does not indicate causal links between trucking worksites' poor environmental health-related supports (eg, few health-promotive resources) and adverse health outcomes (eg, elevated morbidities), our findings do offer further evidence that the trucking sector and settings where truckers work or spend large segments of their days are not conducive to health behavior practices. While for smaller companies, direct support for active living via fitness resources and facilities might be logistically restrictive and cost-ineffective, however, larger firms and national truckstop chains could provide them and by not doing so they are missing a significant marketing opportunity.

Results from relevant environmental assessments of interventions at other workplaces have been equally revealing, especially as most have examined workingclass, blue-collar worksites. While these studies have not necessarily used similar methodologies or instruments, they do nevertheless provide comparative data that is worthy of note. One national health-promotion survey of diverse worksites recorded the presence of about $12 \%$ fitness/walking trails and $15 \%$ fitness centers around the country. ${ }^{28} \mathrm{An}$ assessment of 4 urban bus garages in Minnesota determined all to have fitness rooms, with at least 1 stationary bike and treadmill per site; however, transit workers did not perceive the garages to be supportive of physical activity and weight management, in terms of social and administrative support for such behaviors. ${ }^{5,29}$ Another study assessed 12 large manufacturing and research/development worksites and recorded 14 fitness and physical-activity facilities. ${ }^{30}$ Thirty hotels were assessed to determine associations between employee obesity and the presence of physical-activity resources, however, none of the environmental variables (eg, physical-activity activities offered, availability of low-fat food choices) were found to be related to BMI. ${ }^{31}$ Finally, an environmental assessment of 20 diverse worksites (mail centers, parcel centers, electricity supply organizations, and coal mines) in Australia found that 20 to $25 \%$ of the worksites had exercise rooms, billiard tables, or table tennis on site and $10 \%$ had access to a neighborhood fitness center. ${ }^{32}$ Unfortunately, comparative assessments of 
other trucking work settings do not exist. Foregoing data indicate that while many workplaces do not fully support active living through their policies and resources, there are environmental health disparities among different work environments, with trucking work environments ranking very low.

\section{A Healthier Trucking Sector? A New Paradigm for Health-Promotion}

The low performance of trucking work settings in terms of their support for active-living is not surprising in light of truckers' high morbidity rates. Given that truckers work about 14 hours a day under stringent conditions, the resources and opportunities made available to them during the time they spend at truckstops-where longhaul truckers in particular are mostly confined during their downtimes-are meager at best. In these environments, truckers find mostly unhealthy food items, ${ }^{33}$ scant opportunities for physical or recreational activity, ${ }^{12}$ dangerously poor air quality, ${ }^{34}$ absence of any type of wellness programs, ${ }^{35}$ and no access to healthcare of any type. ${ }^{36}$ This is oftentimes attributable to the fact that these worksites are located in isolated places due to the lack of public transit systems, or in socioeconomically depressed areas with limited health-supportive choices and numerous risk-laden opportunities. ${ }^{37}$ Because increases in obesity rates cannot be explained only by genetic or individual factors, but rather primarily by environmental factors that encourage increased energy intake and decreased energy expenditures, ${ }^{38}$ the need for environmental-level interventions at trucking worksites is incontrovertible.

Although "the workplace" has been identified as a promising setting for the implementation of health promotion programs, no more than 1 in 5 worksites (with a minimum of 50 employees) across the country offers some type of a health promotion program that combines physical activity, healthy eating, and weight management. ${ }^{28}$ Worksite health promotion (WHP) programs focusing on physical activity and nutrition have consistently brought about positive effects on fitness levels, lipids, anthropometric measures, work attendance, and stress. ${ }^{39,40}$ There is compelling evidence to support that significant employer expenditures on healthcare can be lowered as a result of WHP programs.$^{41}$ Numerous benefits of investing in WHP programs include enhanced worker productivity, improved workplace morale, positive changes to workplace culture, reduced absenteeism, improved staff retention, reduced work-related injuries, and reduced medical costs, with anticipated returns on investment ranging from $\$ 3.48$ to $\$ 5.82$ per dollar spent over a 2- to 5-year period. ${ }^{42-45}$

An exhaustive review of wellness programs in the trucking sector reveals only a few, relatively small-scale, inexplicably compartmentalized, inefficiently-run, and mostly underfunded programs that were implemented over the past 2 decades. ${ }^{46}$ While in the 1990 s, a number of trucking companies (ie, Schneider National, JB Hunt, Melton Truck Lines) had initiated various forms of wellness programs for their employees and achieved relatively good results in improving individual health while reducing healthcare costs and increasing productivity, some have since inexplicably discontinued these programs. ${ }^{46}$ In light of truckers' increasingly costly fatal crashes and speculated underlying causes, the federal government (Federal Motor Carrier Safety Administration)—in its efforts to provide supporting evidence for the preventive function of wellness programs - cosponsored the "Gettin' in Gear" program (built around refueling/nutrition, rejuvenating/exercise, relating/social health, and relaxing/mental health) to address risks associated with commercial driving. ${ }^{47}$ Along these lines, the National Institute for Occupational Safety and Health (NIOSH) has planned a national baseline assessment on whether and how occupational exposures can explain truckers' elevated morbid conditions and crashes. ${ }^{48}$

The foregoing discussion and this study's specific findings support the need for comprehensive WHP programs focusing not only on improving the active-living environment of trucking worksites but on promoting an overall healthier work environment for the trucking sector. The current narrow paradigm, ${ }^{48,49}$ which entails mostly an occupational safety approach with a primary focus on accidents and crashes or small-scale, individualtailored wellness programs, ${ }^{46}$ have become obsolete. There is strong evidence to support that WHP programs could be significantly more effective if they integrate occupational safety with health promotion, thereby collectively enhancing both the health and safety of working people. ${ }^{50}$ In the case of truckers, trucking work sites and the overall trucking sector, this paradigm would have a comprehensive scope that integrates occupational health and health promotion, with multiple levels of influence, including the individual, the interpersonal, and the organizational/institutional/ecological levels. This holistic and multicomponent approach to promoting healthier-living would target a wide range of risk factors [ie, smoking, limited access to healthful foods at truckstops, excessive drinking, unhealthy hours of service (HoS), total work hours and needed mandatory breaks, lack of fitness facilities at truckstops] at several intertwined levels: the individual trucker's lifestyle practices, federal government regulations, trucking-sector operations, corporate policies in trucking worksites, the trucking built-environment (including ergonomic truck cab design), and the full spectrum of the trucking work environment. ${ }^{10}$ As per this approach, trucking stakeholders (ie, union leaders, CEOs of trucking companies and truckstops, health insurance firms, NIOSH and FMCSA spokespersons) would be coresponsible for comprehensive and evolving worksite health promotions with integrated monitoring and evaluation components. The main thrust of this rationale incorporates the fact that WHP and occupational safety and health provide 2 parallel pathways for promoting 
trucker health, which will be significantly strengthened when they are coordinated and integrated rather than separate and independent. ${ }^{50}$

\section{Conclusions}

Findings of this small-scale assessment of environmental barriers to active living in the trucking sector is supported by accumulating anecdotal and empirical evidence that suggests that trucking work settings remain highly unhealthy places. Our assessment of the physical, social, and information environments of trucking worksites, as well as the physical environment of surrounding communities, reveals only limited opportunities for involvement in physical and recreational activity, sports or exercise. It is especially surprising that truckstop companies in particular remain detached from the needs of their primary customers and miss opportunities for improved customer service and satisfaction, thereby increasing their own revenues.

Those immersed in the trucking sector, should not be surprised by these findings, primarily because truckers' alarmingly high morbidities lend credence to what is reported here. This highly underserved occupational segment of the U.S. labor force along with several million people employed by the transportation and warehousing sector have been neglected by the federal government, business leaders, and health professionals. There is sufficient supporting evidence for across-the-board, comprehensive multistakeholder health-promotion interventions that simultaneously target the plethora of intertwined risk factors associated with trucking occupational milieux. A multistakeholder, multilevel approach that incorporates WHP and occupational safety and health, and goes beyond individual trucker lifestyles, is a public-health need in light of severe occupational health disparities.

\section{References}

1. Centers for Disease Control and Prevention. Healthy weight-it's not a diet, it's a lifestyle! 2009. Available at: http://www.cdc.gov/healthyweight/physical_activity/ index.html. Accessed March 15, 2010.

2. Finkelstein EA, Trogdon JG, Cohen JW, Dietz W. Annual medical spending attributable to obesity: payer-and service-specific estimates. Health Aff. 2009;28:w822-w831.

3. Lee IM, Djoussé L, Sesso HD, Wang L, Buring JE. Physical activity and weight gain prevention. JAMA. 2010;303:1173-1179.

4. Ball B, Timperio AF, Crawford DA. Understanding environmental influences on nutrition and physical activity behaviors: where should we look and what should we count? Int J Behav Nutr Phys Act. 2006;3:33.

5. French SA, Harnack LJ, Toomey TL, Hanna PJ. Association between body weight, physical activity, and food choices among metropolitan transit workers. Int J Behav Nutr Phys Act. 2007;4:52.

6. Pratt M, Epping JN, Dietz WH. Putting physical activity into public health: a historical perspective from the CDC. Prev Med. 2009;49:301-302.
7. Transportation Research Board. TRB special report 282: does the built environment influence physical activity? Examining the evidence. Washington, DC: Transportation Research Board; 2005.

8. Popkin BM, Duffey K, Gordon-Larsen P. Environmental influences on food choice, physical activity and energy balance. Physiol Behav. 2005;86:603-613.

9. Pronk NP, Kottke TE. Physical activity promotion as a strategic corporate priority to improve worker health and business performance. Prev Med. 2009;49:316-321.

10. Apostolopoulos Y, Sönmez S, Shattell M, Belzer MH. Worksite-induced morbidities among truck drivers in the United States. AAOHN J. 2010;58(7): 285-296.

11. Bigert C, Gustavsson P, Hallqvist J, et al. Myocardial infarction among professional drivers. Epidemiology. 2003; 14:333-339.

12. Brewster RM. American Transportation Research Institute. Ohio Trucking Safety Council: American Transportation Research Institute; 2007.

13. Robinson C, Burnett CA. Truck drivers and heart disease in the United States, 1979-1990. Am J Ind Med. 2005;47:113-119.

14. Salzman GM, Belzer MH. Truck driver occupational safety and health: 2003 Conferencereport and selective literature review (Publication No. 2007-120). U.S. Department of Health and Human Services, Centers for Disease Control and Prevention, National Institute for Occupational Safety and Health; 2007.

15. Martin BC, Church TS, Bonnell R, Ben-Joseph R, Borgstadt $\mathrm{T}$. The impact of overweight and obesity on the direct medical costs of truck drivers. J Occup Environ Med. 2009;51:180-184.

16. Krieger N. Epidemiology and the web of causation: has anyone seen the spider? Soc Sci Med. 1994;39:887-903.

17. McMichael AJ. Prisoners of the proximate: loosening the constraints on epidemiology in an age of change. Am J Epidemiol. 1999;149:887-897.

18. Susser M. Choosing a future for epidemiology: from black boxes to Chinese boxes and eco-epidemiology. Am J Public Health. 1996;86:674-677.

19. Apostolopoulos Y. Healthy Trucking Worksites Audit Instrument (HEATWAI): Assessment of food and physicalactivity environments in the transportation and warehousing sector. Unpublished manuscript, University of North Carolina at Greensboro, Greensboro, NC; 2010.

20. Apostolopoulos Y, Sönmez S. Trucker risk networks, drug use, and transmission of STIs/BBIs: Preliminary findings from the first epidemiological investigation in North America. Atlanta, GA: Mobility and Population Health Unit, Emory University School of Medicine; 2006.

21. French SA, Story M, Jeffery RW. Environmental influences on eating and physical activity. Annu Rev Public Health. 2001;22:309-335.

22. Barnett E, Anderson T, Blosnich J, Menard J, Halverson J, Casper M. Heart healthy and stroke free: a social environment handbook. Atlanta, GA: U.S. Department of Health and Human Services, Centers for Disease Control and Prevention; 2007.

23. Krieger N. Workers are people too: societal aspects of occupational health disparities:An ecosocial perspective. Am J Ind Med. 2010;53:104-115.

24. Larson N, Story MT, Nelson MC. Neighborhood environments: disparities in access to healthy foods in the US. Am J Prev Med. 2009;36:74-81. 
25. Macintyre S. Deprivation amplification revisited; or, is it always true that poorer places have poorer access to resources for healthy diets and physical activity? Int $J$ Behav Nutr Phys Act. 2007;4:32-38.

26. Taylor AH, Dorn L. Stress, fatigue, health and risk of road traffic accidents among professional drivers: The contribution of physical inactivity. Annu Rev Public Health. 2006;27:371-391.

27. Wiegand DM, Hanowski RJ, McDonald SE. Commercial drivers' health: A naturalistic study of body mass index, fatigue, and involvement in safety-critical events. Traffic Inj Prev. 2009;10:573-579.

28. Linnan L, Bowling M, Childress J, et al. Results of the 2004 national worksite health promotion survey. Am J Public Health. 2008;98:1503-1509.

29. Shimotsu ST, French SA, Gerlach AF, Hannan PJ. Worksite environment physical activity and healthy food choices: measurement of the worksite food and physical activity environment at fours metropolitan bus garages. Int J Behav Nutr Phys Act. 2007;4:17-23.

30. Parker KB, DeJoy DM, Wilson MG, Bowen HM, Goetzel RZ. Application of the environmental assessment tool (EAT) as a process measure for a worksite weight management intervention. J Occup Environ Med. 2010;52:S42S51.

31. Nigg CR, Albright C, Williams R, et al. Are physical activity and nutrition indicators of the Checklist of the health promotion environments at worksites (CHEW) associated with employee obesity among hotel workers? J Occup Environ Med. 2010;52:S4-S7.

32. Oldenburg B, Sallis JF, Harris D, Owen N. Checklist of health promotion environments at worksites (CHEW): Development and measurement characteristics. Am J of Health Prom. 2002;16:288-299.

33. Whitfield Jacobson PJ, Prawitz AD, Lukaszuk JM. Longhaul truck drivers want healthful meal options at truck-stop restaurants. J Am Diet Assoc. 2007;107:2125-2129.

34. Davis ME, Smith TJ, Laden F, et al. Driver exposure to combustion particles in the US trucking industry. J Occup Environ Hyg. 2007;4:848-854.

35. Perry B, Garratt BL. Driver health: roadmap to wellness. Roadside Medical's White Paper. 2010. Available at: http://www.roadsidemed.com/Portals/0/Roadside\%20\%20ATA\%20Driver\%20Health.pdf. Accessed March 15, 2010.

36. Solomon AJ, Doucette JT, Garland E, McGinn T. Healthcare and the long haul: long-distance truckers-a medically underserved population. Am J Ind Med. 2004;46:463-471.

37. Apostolopoulos Y, Sönmez S. Tracing the diffusion of infectious diseases in the transport sector. In: Apostolopoulos Y, Sönmez S, eds. Population mobility and infectious disease. New York: Springer; 2007:131-156.
38. Hill JO, Peters JC. Environmental contributions to the obesity epidemic. Science. 1998;280:1371-1374.

39. Conn VS, Hafdahl AR, Cooper PS, Brown LM, Lusk SL. Meta-analysis of workplace physical activity interventions: 2005 update. Am J Prev Med. 2009;37:330-339.

40. Pratt CA, Lemon SC, Fernandez ID, et al. Design characteristics of worksite environmental interventions for obesity prevention. Obesity (Silver Spring). 2007;15:21712180.

41. Hunnicutt D. The cost of wellness: A WELCOA expert interview with Dr Ron Goetzel. Absolute Advantage, 7:10. 2009. Available at: http://www.absoluteadvantage.org/ article/?article=277. Accessed March 15, 2010.

42. Batt M. Physical activity interventions in the workplace: the rationale and future direction for workplace wellness. Br J Sports Med. 2009;43:47-48.

43. Bellew, B. Primary prevention of chronic disease in Australia through interventions in the workplace setting: a rapid review. Sax Institute for the Chronic Disease Prevention Unit, Victorian Government Department of Human Services; 2008.

44. Chapman L. Meta-evaluation of worksite health promotion economic return studies. Am J Health Promot. 2005;19:1-15.

45. Hooper P, Bull FC. Healthy active workplaces: review of evidence and rationale for workplace health. Department of Sport Recreation, Western Australia Government; 2009.

46. Krueger G, Brewster R, Dick V, Inderbitzen R, Staplin L. Commercial truck and bus safety synthesis program synthesis 15: health and wellness programs for commercial drivers. Washington, DC: Transportation Research Board; 2007.

47. Krueger G, Brewster R. Gettin' in gear: wellness, health, and fitness program for commercial drivers: instructors manual. Alexandria, VA: American Transportation Research Institute and Federal Motor Carrier Safety Administration; 2002.

48. Sieber WK. NIOSH science blog: Truck driver safety and health. 2007. Available at: http://www.cdc.gov/niosh/blog/ nsb111907_truck.html. Accessed March 15, 2010.

49. Federal Motor Carrier Safety Administration. Hoursof-service regulations. 2005. Available at: http://www. fmcsa.dot.gov/rules-regulations/topics/hos/hos-2005.htm. Accessed March 15, 2010.

50. Sorensen G, Barbeau EM. Integrating occupational health, safety and worksite health promotion: opportunities for research and practice. Med Lav. 2006;97:240-257. 